\title{
Integração e convergência das tecnologias de comunicação e informação como motivador no processo ensino-aprendizagem na disciplina de botânica agrícola'
}

Integration and convergence of communication and information technologies as a motto in the learning-teaching process in the discipline of agricultural botany

\section{Juçara Terezinha Paranhos²}

I Trabalho referente ao Edital n. I7/NTE/UAB - 2012

2 Professora Associada I, Departamento de Biologia, Centro de Ciências Naturais e Exatas, Universidade Federal de Santa Maria. E-mail: jtparanhos@gmail.com

\section{Resumo}

Nos últimos anos tem-se notado uma desmotivação por parte dos alunos nas aulas presenciais da graduação, refletindo no desestímulo dos docentes e negativamente no processo ensino/aprendizagem, aumentando o número de reprovações nas disciplinas e/ou desistência dos cursos no qual eles estão inseridos. Assim, o trabalho teve como objetivo Investigar a contribuição de práticas pedagógicas convencionais aliadas aos recursos tecnológicos da informação e comunicação como mediadoras e motivadoras neste processo para alunos do Curso de Graduação em Agronomia da UFSM. O estudo foi desenvolvido no primeiro semestre letivo de 2012, na disciplina BLG 1035 - Botânica Agrícola, com duas repetições (turmas 11 e 12), com 21 alunos cada. No primeiro bimestre, as duas turmas receberam o conteúdo programático da disciplina constante no Projeto Pedagógico do Curso, bem como as avaliações no modo convencional (100\% presencial). No segundo bimestre, o conteúdo foi desenvolvido na forma presencial integrado à modalidade à distância, mediada pelo Moodle (Modular Object-Oriented Dynamic Learning Environment) e as avaliações do conteúdo constituíram-se de atividades presenciais e virtuais, com pesos iguais (50\% cada). Além disso, ao término do semestre, foram desenvolvidas outras três formas de avaliações. As duas turmas apresentaram médias acima de 7,0 quanto ao nível de competência e habilidade do uso dos recursos da tecnologia da comunicação e informação aplicada à educação. Quanto ao uso das TICs como motivadora no processo ensino-aprendizagem observou-se diferenças nas opiniões entre as duas turmas. Palavras Chave: hipertexto, hipermídia, MOODLE, eletromagnetismo, objetos educacionais, ensino de física, motor elétrico, ensino a distância, ambientes virtuais de aprendizagem.

\begin{abstract}
In recent years we have noticed a loss of motivation on the part of students in the undergraduate classroom, reflecting on the teaching staff and negatively discouraging in the teaching/learning process, increasing the number of Deprecations in the disciplines and/or abandonment of the courses in which they are inserted. Thus, the work aimed to Investigate the contribution of conventional Allied pedagogical practices to information and communication technology resources as mediators and motivating in this process to students of undergraduate degree in agronomy from UFSM. The study was carried out in the first half of 2012, in school discipline BLG 1035-Agricultural Botany, with two repetitions (classes 11 and 12), with 21 students each. In the first quarter, the two classes were given the programmatic content of the discipline at the pedagogic project of the course, as well as the evaluations in the conventional way ( $100 \%$ attendance). In the second quarter, the content has been developed as an integrated distance mode in person, mediated by Moodle (Modular Object-Oriented Dynamic Learning Environment) and content assessments had consisted of in-person and virtual activities, with equal weights ( $50 \%$ each). In addition, at the end of the semester, were developed three other forms of evaluations. The two classes had averages above 7.0 on the level of competence and skill of the use of information and communication technology applied to education. As for the use of ICTs as motivating in the teaching-learning process we observed differences in views between the two groups.
\end{abstract}

Keywords: Information and communication technology. Teaching and learning in the virtual environment, Teaching and learning in classroom environment. 


\section{INTRODUÇÃO}

A Educação à Distância (EAD) nas universidades é uma das principais políticas de expansão e interiorização do ensino superior público, gratuito e de qualidade. Desde 2005 a Universidade Federal de Santa Maria (UFSM) integrou-se ao Sistema Universidade Aberta do Brasil (UAB) tendo, portanto uma cultura já consolidada ao ambiente virtual de ensino-aprendizagem, o que vem garantindo a implantação e consolidação de cursos de graduação e pós-graduação nesta modalidade, tanto no âmbito interno como externo à Instituição. Estas ações vêm sendo ampliadas para várias cidades pólo no estado do Rio Grande do Sul, bem como para outros estados, respondendo essa política adotada pela UFSM não somente ao fomento do Ministério da Educação, mas à demanda da sociedade brasileira.

Segundo SAMPAIO \& LEITE (1999) o papel da educação deve voltar-se para a democratização do acesso ao conhecimento, produção e interpretação das tecnologias, suas linguagens e consequências. Para KENSKI (2010), a educação é um mecanismo poderoso de articulação das relações entre poder, conhecimento e tecnologia. Entretanto, para isso torna-se necessário preparar o professor para utilizar pedagogicamente as tecnologias na formação de cidadãos que deverão produzir e interpretar as novas linguagens do mundo atual e futuro.

Nos últimos anos tem-se notado uma desmotivação por parte dos alunos nas aulas presenciais, o que reflete no desestímulo dos docentes em melhorar sua aula e ministrá-la da melhor forma possível. Isso vem afetando de forma negativa o processo de aprendizagem pelos estudantes, aumentando o número de reprovações nas disciplinas e/ou desistência dos cursos no qual eles estão inseridos. Atualmente, a disponibilidade de tecnologias atrativas aos jovens associada ainda ao fato de que os métodos de ensino convencionais já não agradam os alunos de hoje tem contribuído para que isso aconteça. Para alguns educadores, os desafios contemporâneos requerem um repensar da educação, diversificando os recursos utilizados, oferecendo novas alternativas para os indivíduos interagirem e se expressarem, diversificando as formas de agir e de aprender, considerando a cultura e os meios de expressão que a permeiam. Segundo MORAES \& VARELA (2006), esta desmotivação interfere negativamente no processo de ensino-aprendizagem, e entre as causas da falta de motivação, o planejamento e o desenvolvimento das aulas realizadas pelo professor são fatores determinantes. ANTUNES (2010) pressupõe que, para o docente conseguir despertar a atenção dos estudantes é preciso estar atento ao seu cotidiano e, mais, integrado às mudanças tecnológicas.

Atualmente, sabe-se que o uso de tecnologias como apoio ao ensino e à aprendizagem, mediado pelo Moodle (Modular Object-Oriented Dynamic Learning Environment) pode aumentar ainda mais os índices de qualidade nos cursos presenciais e à distância por proporcionar ampla possibilidade de interação e colaboração em torno dos conteúdos estabelecidos nos programas dos Projetos Pedagógicos dos Cursos. Neste contexto, o incentivo à integração das tecnologias educacionais nas modalidades presencial e à distância é de suma importância, permitindo ao docente ampliar seu trabalho, possibilitando problematizar, refletir e criar soluções para a integração metodológica e convergência das tecnologias de comunicação e informação na organização do processo educativo presencial. Isto implica em investir na elaboração, seleção e implementação de materiais didáticos no escopo hipermidiático. Além disso, permite a participação ativa dos estudantes efetivada a partir de questionamentos, problematizações, discussões, dúvidas e compartilhamento de saberes nas atividades propostas. Ressalta-se que desenvolver essas habilidades nos estudantes vai além da vida acadêmica, estendendo-se para o mundo do trabalho e para formação do ser humano, interferindo positivamente num melhor convívio social.

A interface entre educação e tecnologia já é contemplada na LDB e o desenvolvimento de materiais didáticos que problematizem os modos de comunicação e compartilhamento da informação permeados pela integração e convergência das tecnologias de comunicação e informação, são possibilidades de renovar culturalmente os conteúdos curriculares dos cursos de graduação nas universidades. A implementação de uma iniciativa cultural que está em sintonia com o Plano de Desenvolvimento Institucional da UFSM (PDI UFSM 2011-2015) à medida que se compromete em "dar condições para a implementação de práticas acadêmicas que contribuam para o benefício social", reconhecendo como "sendo necessário que a universidade se organize internamente, em coerência com seus objetivos e em favor de sua interação com o contexto, contribuindo fundamentalmente com a valorização do desenvolvimento humano, científico e tecnológico". Além disso, o incentivo para criar e incrementar uma cultura acadêmica, que tenha na mediação dos recursos tecnológicos educacionais para Internet 
um instrumento útil para otimizar a docência universitária, pode promover a dinamização de materiais didáticos que favoreçam a autonomia de aprendizado nos estudantes e a melhoria da qualidade no ensino de graduação na UFSM.

Neste contexto, o objetivo do estudo foi Investigar a contribuição de práticas pedagógicas convencionais e inovadoras que utilizam recursos da tecnologia da informação e comunicação (TIC), como mediadores e motivadores do processo ensino-aprendizagem para alunos do Curso de Graduação em Agronomia da UFSM.

\section{MATERIAIS E MÉTODOS}

O estudo foi desenvolvido na disciplina BLG 1035 - Botânica Agrícola, ministrada aos alunos do segundo semestre do Curso de Agronomia, Centro de Ciências Rurais da Universidade Federal de Santa Maria. A disciplina constou de duas horas de aulas teóricas e três horas de aulas práticas, oferecida para duas turmas, 11 e 12, cada uma com 21 alunos matriculados regularmente no primeiro semestre letivo de 2012.

No primeiro bimestre as duas turmas receberam o conteúdo programático da disciplina constante no Projeto Pedagógico do Curso, no modo convencional, constando de aulas teóricas presenciais expositivas, utilizando-se recursos áudio-visuais, estudos dirigidos e discussão dos mesmos em sala de aula. Nas aulas práticas presenciais, os alunos desenvolveram atividades que constaram da coleta individual de espécies vegetais de interesse agronômico em seu habitat; diagnose do material botânico, estudando nessas espécies as características vegetativas e reprodutivas, ambas observadas a olho nú e/ou utilizando aparelhos microscópio estereoscópios (lupas). Após, utilizando Chaves de Identificação segundo APG III (Souza \& Lorenzi, 2012) foram identificados os táxons família, gênero e espécie. Simultaneamente, os materiais botânicos foram herborizados (prensagem e secagem) e fixados em capas de papel contendo uma ficha de classificação e identificação das espécies, sendo então, entregue para avaliação.

No segundo bimestre, o conteúdo foi desenvolvido na forma presencial integrado à modalidade à distância e as avaliações do conteúdo constituíram-se de atividades presenciais e virtuais, com pesos iguais ( $50 \%$ cada). Esta integração ocorreu através do desenvolvimento dos conteúdos programáticos em sala de aula e a seleção e reelaboração de textos hipermidiáticos relacionados ao conteúdo teórico-prático da disciplina e disponibilizados aos alunos, via Moodle, bem como tarefas e atividades como elaboração de um glossário botânico com os termos utilizados na disciplina; elaboração de trabalhos colaborativos e confecção de slides usando programa Power Point para apresentação dos mesmos na forma de seminários na modalidade presencial e previamente enviados aos colegas, além de pesquisas em artigos científicos disponíveis na internet (Periódicos CAPES) relacionados ao conteúdo programático, detectando possíveis erros taxonômicos e de nomenclatura, os quais foram disponibilizados no ambiente virtual e textualizadas discussões sobre os mesmos.

Finalizadas as atividades presenciais e à distância, foram então desenvolvidas três formas de avaliações com os alunos: na primeira, foi aplicado aos alunos um questionário avaliativo do docente, proposto por BARROS (2009) e descrito no Quadro 1, com o intuito de identificar a eficiência do uso das TICs como motivadoras no processo de ensino-aprendizagem. Na segunda avaliação, foi aplicado outro questionário avaliativo aos alunos (Quadro 2), com o objetivo de avaliar a influência do uso de tecnologia como mediador motivacional no processo de ensino-aprendizagem e comparar com o uso convencional de ministrar os conteúdos pelo docente (modalidade presencial). Além disso, identificar as vantagens e dificuldades encontradas pelos mesmos do uso do ambiente virtual neste processo. $\mathrm{Na}$ terceira avaliação, foi computado o desempenho de cada aluno nas modalidades presenciais através de provas teóricas e práticas, estudos dirigidos e discussões dos mesmos, apresentação e discussão dos seminários. Na modalidade à distância, foi observado o desempenho de cada aluno pelas notas atribuídas às tarefas e atividades disponibilizadas no ambiente virtual. Após a coleta dos dados, os mesmos foram analisados estatisticamente utilizando o programa SPSS 10.0, sendo consideradas duas repetições por bimestre (Turma 11 e turma 12) e o tamanho da amostragem em cada repetição correspondeu aos 21 alunos em cada turma.

\section{RESULTADOS E DISCUSSÃO}

No primeiro bimestre, as duas turmas matriculadas receberam, no modo convencional (aulas teóricas e práticas presenciais), $100 \%$ do conteúdo programático da disciplina e $100 \%$ das avaliações do mesmo. No segundo bimestre, o conteúdo programático e as avaliações foram desenvolvidos 
QUADRO 1 - Avaliações feitas pelos alunos, referente ao professor, quanto à classificação do nível de competência e habilidade do uso dos recursos da tecnologia da comunicação e informação aplicados à educação, adaptação de BARROS (2009).

\begin{tabular}{|c|c|c|c|}
\hline \multirow[b]{2}{*}{ Classificação } & \multirow[b]{2}{*}{$\begin{array}{l}\text { Tecnologias para o processo de ensino- } \\
\text { aprendizagem }\end{array}$} & \multicolumn{2}{|c|}{ AVALIAÇÃO - PROFESSOR } \\
\hline & & Turma $11^{*}$ & Turma $12^{* *}$ \\
\hline Técnico para si & $\begin{array}{l}\text { Utiliza a tecnologia de forma básica e } \\
\text { para si próprio }\end{array}$ & $7,29 \mathrm{a} * * *$ & $8,30 \mathrm{a}$ \\
\hline Técnico + Pedagógico & $\begin{array}{l}\text { Utiliza a tecnologia como recurso para o } \\
\text { trabalho docente }\end{array}$ & $8,71 \mathrm{a}$ & $8,80 \mathrm{a}$ \\
\hline Pedagógico como apoio & $\begin{array}{l}\text { Utiliza a tecnologia como apoio no } \\
\text { trabalho da sala de aula, elaborando } \\
\text { materiais ou pesquisando informações } \\
\text { para o desenvolvimento do conteúdo e } \\
\text { das atividades de ensino }\end{array}$ & $8,71 \mathrm{a}$ & $8,90 \mathrm{a}$ \\
\hline Pedagógico mediado & $\begin{array}{l}\text { Utiliza a tecnologia como produtora e } \\
\text { facilitadora na construção do } \\
\text { conhecimento }\end{array}$ & $8,07 \mathrm{a}$ & $8,60 \mathrm{a}$ \\
\hline $\begin{array}{l}\text { Transdiciplinaridade, } \\
\text { autonomia e virtualização } \\
\text { de ensino aprendizagem }\end{array}$ & $\begin{array}{l}\text { Utiliza a tecnologia como mediadora na } \\
\text { produção de conhecimento, ampliando } \\
\text { as potencialidades de ensino com uso } \\
\text { dos conteúdos e formas disponibilizadas } \\
\text { pela tecnologia. }\end{array}$ & $7,00 \mathrm{a}$ & $8,60 \mathrm{a}$ \\
\hline MÉDIA & & 7,96 & 8,64 \\
\hline
\end{tabular}

* Segunda coluna refere-se à média das notas de 07 (sete) alunos da Turma 11;

** Terceira coluna refere-se à média das notas de 17 (dezessete) alunos da Turma 12;

*** Letras iguais não diferem pelo Teste de Duncan ( $\mathrm{p} \leq 0.05$ ), programa estatístico SPSS 10.0.

$100 \%$ na forma presencial integrada com a modalidade à distância, sendo o peso das avaliações iguais (50\% para cada modalidade). Para o desenvolvimento dessa integração e convergência das tecnologias de comunicação e informação foram selecionados e reelaborados materiais didáticos (hipermídias educacionais) programados como recursos e atividades em ambientes virtuais de ensino-aprendizagem. A disponibilização virtual (Moodle) deste material bem como as tarefas e/ou atividades permitiria aos alunos entrarem em contato com o conteúdo anteriormente à apresentação do mesmo no ambiente presencial, possibilitando maior compreensão no sentido de qualificar as discussões em sala de aula, pelo maior tempo disponível aos alunos para dedicarem-se aos assuntos pré-determinados e a possibilidade de maior intercâmbio com os colegas proporcionando trocas de idéias sobre os conteúdos, fortalecendo o diálogo-problematizador. Ao término do semestre letivo, finalizadas as atividades presenciais e à distância, foram desenvolvidas três formas de avaliações, com valores de 0 a 10 , sendo duas referentes à questões aplicadas aos alunos e uma relativa ao desempenho de cada aluno, na forma presencial, através de provas teóricas e práticas, estudos dirigidos, discussões, apresentação e discussão de seminários, bem como, na modalidade a distância, através das notas atribuídas a cada tarefa disponibilizada via Moodle.

Os quadros 1 e 2 mostram as avaliações feitas pelos alunos das turmas 11 e 12, referente ao professor e aos alunos, respectivamente, quanto à classificação do nível de competência e habilidade do uso dos recursos da tecnologia e informação aplicados à educação. Observa-se que não houve diferença significativa entre as notas atribuídas pelas turmas 11 e 12 quanto ao nível de competência e habilidade no uso desses recursos. Embora não havendo estatisticamente diferença entre as notas, pode-se verificar que as notas atribuídas pela Turma 12, tanto em relação ao professor quanto ao aluno, sempre foram maiores, apresentando uma média de 8,64 e 8,84 , respectivamente. As duas turmas atribuíram a maior nota, 8,71 e 8,90, respectivamente pelas turmas 11 e 12 , à utilização das TICs pelo professor, como apoio no trabalho em sala de aula através da elaboração de materiais ou da busca de informações para o desenvolvimento do conteúdo e das atividades de ensino. Entretanto, 
Quadro 2 - Avaliações feitas pelos alunos, referente aos mesmos, quanto à classificação do nível de competência e habilidade do uso dos recursos da tecnologia da comunicação e informação aplicados à educação, adaptação de BARROS (2009).

\begin{tabular}{|c|c|c|c|}
\hline \multirow[b]{2}{*}{ Classificação } & \multirow[b]{2}{*}{$\begin{array}{l}\text { Tecnologias para o processo de ensino- } \\
\text { aprendizagem }\end{array}$} & \multicolumn{2}{|c|}{ AVALIAÇÃO - ALUNOS } \\
\hline & & Turma 11* & Turma $12 * *$ \\
\hline Técnico para si & $\begin{array}{l}\text { Utiliza a tecnologia de forma básica e para } \\
\text { si próprio }\end{array}$ & $7,36 \mathrm{a}$ & $8,70 \mathrm{a}$ \\
\hline Técnico + Pedagógico & $\begin{array}{l}\text { Utiliza a tecnologia como recurso para o } \\
\text { trabalho docente }\end{array}$ & $7,43 \mathrm{a}$ & $8,90 \mathrm{a}$ \\
\hline Pedagógico como apoio & $\begin{array}{l}\text { Utiliza a tecnologia como apoio no } \\
\text { trabalho da sala de aula, elaborando } \\
\text { materiais ou pesquisando informações } \\
\text { para o desenvolvimento do conteúdo e das } \\
\text { atividades de ensino }\end{array}$ & $7,00 \mathrm{a}$ & $9,10 \mathrm{a}$ \\
\hline Pedagógico mediado & $\begin{array}{l}\text { Utiliza a tecnologia como produtora e } \\
\text { facilitadora na construção do } \\
\text { conhecimento }\end{array}$ & $7,86 \mathrm{a}$ & $8,80 \mathrm{a}$ \\
\hline $\begin{array}{l}\text { Transdiciplinaridade, } \\
\text { autonomia e virtualização } \\
\text { de ensino aprendizagem }\end{array}$ & $\begin{array}{l}\text { Utiliza a tecnologia como mediadora na } \\
\text { produção de conhecimento, ampliando } \\
\text { as potencialidades de ensino com uso dos } \\
\text { conteúdos e formas disponibilizadas pela } \\
\text { tecnologia. }\end{array}$ & $7,14 \mathrm{a}$ & $8,70 \mathrm{a}$ \\
\hline & MÉDIA & 7,36 & 8,84 \\
\hline
\end{tabular}

\footnotetext{
* Segunda coluna refere-se à média das notas de 07 (sete) alunos da Turma 11;

** Terceira coluna refere-se à média das notas de 17 (dezessete) alunos da Turma 12;

*** Letras iguais não diferem pelo Teste de Duncan $(\mathrm{p} \leq 0.05)$, programa estatístico SPSS 10.0 .
}

quando esta questão refere-se ao aluno, foi-lhe atribuída a nota mais baixa pela turma $11(7,00)$, ao contrário da turma 12 , na qual se verificou a maior nota $(9,00)$. A mesma nota 7,0 (menor nota) também foi dada pela turma 11 ao professor quanto à utilização pelo mesmo da tecnologia como mediadora na produção de conhecimento, ampliando as potencialidades de ensino com uso dos conteúdos e formas disponibilizadas pela tecnologia e nota 7,14 para os próprios alunos, demonstrando que o uso das TICs via Moodle foi importante e satisfatória como apoio no desenvolvimento do conteúdo programático e apresentação na forma presencial, porém não contribuiu na mesma proporção para ampliar o conhecimento ou o entendimento do conteúdo desenvolvido. Estas respostas não foram observadas na turma 12 , corroborando com Antunes (2010), onde pressupõe que, para o docente conseguir despertar a atenção dos estudantes é preciso estar atento ao seu cotidiano $\mathrm{e}$, mais, integrado às mudanças tecnológicas. Para KENSKI (2010), a educação é um mecanismo poderoso de articulação das relações entre poder, conhecimento e tecnologia. Entretanto, as respostas evidenciadas no questionário demonstraram que, para um resultado satisfatório no uso desta integração, torna-se necessário preparar o professor para utilizar pedagogicamente as tecnologias na formação de cidadãos, e estes deverão produzir e interpretar as novas linguagens do mundo atual e futuro. Portanto, os desafios contemporâneos requerem um repensar da educação, diversificando os recursos utilizados, oferecendo novas alternativas para os indivíduos interagirem e se expressarem, diversificando as formas de agir e de aprender, considerando a cultura e os meios de expressão que a permeiam (MARTINSI, 2008). Conforme ALMEIDA \& PRADO, 2009, o avanço da tecnologia permite que o acesso à informação ocorra de forma mais rápida e fácil, e, como não poderia ser diferente, o meio acadêmico também é atingida e os recursos didáticos tradicionais já não são mais as únicas ferramentas utilizadas em sala de aula. Os autores ainda afirmam que o uso de tecnologias como apoio ao ensino e à aprendizagem vem evoluindo vertiginosamente nos últimos anos, podendo trazer efetivas contribuições à educação, presencial ou à distância. Porém, isso não foi verificado na turma 11 , demonstrando que o aluno também deve estar preparado para estas mudanças no sentido de usufruí-las.

O Quadro 3 refere-se ao uso das TICs como 
QUADRO 3: Avaliações feitas pelos alunos referente ao uso de tecnologia como mediador motivacional no processo de ensino-aprendizagem.

\begin{tabular}{|c|c|c|}
\hline Classificação & Turma $11^{*}$ & Turma $12^{* *}$ \\
\hline $\begin{array}{l}\text { Apresentação do conteúdo programático da discipli- } \\
\text { na no modo convencional e } 100 \% \text { presencial. }\end{array}$ & $9,21 \mathrm{a}^{* * *}$ & 8,20 a \\
\hline $\begin{array}{l}\text { Apresentação do conteúdo programático da discipli- } \\
\text { na na forma presencial integrada à modalidade a } \\
\text { distância com o apoio do Moodle }\end{array}$ & $5,43 \mathrm{~b}$ & 8,40 a \\
\hline $\begin{array}{l}\text { Uso de tecnologias mediado pelo Moodle na apre- } \\
\text { sentação da disciplina contribuiu para a melhoria no } \\
\text { processo ensino-aprendizagem }\end{array}$ & $4,57 \mathrm{~b}$ & $8,70 a$ \\
\hline $\begin{array}{l}\text { Vantagens da Integração das Tecnologias } \\
\text { Educacionais e Convergência entre as modalidades } \\
\text { presencial e à distância. }\end{array}$ & $5,71 \mathrm{~b}$ & 8,70 a \\
\hline $\begin{array}{l}\text { A forma de apresentação da disciplina na forma pre- } \\
\text { sencial e à distância foi motivador na aprendizagem }\end{array}$ & $5,14 \mathrm{~b}$ & 8,50 a \\
\hline $\begin{array}{l}\text { Dificuldades no acesso à internet e ao Moodle na } \\
\text { UFSM. }\end{array}$ & $6,71 \mathrm{~b}$ & 8,60 a \\
\hline $\begin{array}{l}\text { Facilidades no acesso à internet e ao Moodle na } \\
\text { UFSM. }\end{array}$ & $5,14 \mathrm{~b}$ & 8,50 a \\
\hline
\end{tabular}

* Segunda coluna refere-se à média das notas de 07 (sete) alunos da Turma 11;

** Terceira coluna refere-se à média das notas de 17 (dezessete) alunos da Turma 12;

*** Letras iguais não diferem pelo Teste de Duncan $(\mathrm{p} \leq 0.05)$, programa estatístico SPSS 10.0 .

motivadora no processo ensino-aprendizagem, que é o objetivo principal deste estudo, utilizando-se o Moodle como apoio ao ensino presencial e modalidade a distância. Pode-se observar que com exceção da questão 1, a qual refere-se a opinião dos alunos quanto à apresentação e avaliação do conteúdo programático da disciplina no modo convencional (100\% presencial), nas demais questões houve diferença significativa entre todas as notas atribuídas pelas turmas 11 e 12 . A turma 11 atribuiu notas mais baixas a todas as questões $(4,57$ a 6,71 ), ao contrário da turma 12 , onde as notas atribuídas foram altas, variando entre 8,20 a 8,70. Para a turma 11 e ao contrário da turma 12, o uso do Moodle como apoio na apresentação da disciplina não contribuiu para a melhoria no processo ensino-aprendizagem, onde atribuíram a nota mais baixa de todas as questões $(4,57)$. Também segundo eles, o desenvolvimento do conteúdo programático da disciplina através da integração das tecnologias também não foi satisfatória, atribuindo nota 5,43 (questão 2). Convém salientar que embora conste no quadro esta questão, o conteúdo programático foi ministrado $100 \%$ na forma presencial, porém conteúdos, tarefas e atividades foram desenvolvidos através do moodle como complementação do conhecimento, porém, as avaliações presenciais e as atividades a distância tiveram ambas peso 5,0 . Esse resultado contraria os pressupostos educacionais comentados por Martinsi (2008), nos quais os desafios contemporâneos requerem um repensar da educação, diversificando os recursos utilizados, oferecendo novas alternativas para os indivíduos interagirem e se expressarem. Segundo a autora, repensar a educação envolve diversificar as formas de agir e de aprender, considerando a cultura e os meios de expressão que a permeiam. $\mathrm{O}$ uso de mídia em contextos educacionais requer práticas que instiguem novas possibilidades de aprendizagem e a vivência de processos criativos, com diálogos e interações múltiplas.

Nos Quadros 4 e 5 encontram-se as avaliações dos alunos durante todo o semestre, nas duas modalidades para as turmas 11 e 12 , respectivamente. Observa-se que no primeiro bimestre, quando o conteúdo e as avaliações foram $100 \%$ presenciais, dezoito alunos dos 21 matriculados na turma 12 obtiveram notas entre 7,21 e 9,45 enquanto que na turma 11 , apenas cinco alunos tiveram notas entre 7,30 e 8,99. Os demais ficaram com notas baixas, chegando a 2,41. Para esta turma, no segundo bimestre, com o conteúdo 
QUADRO 4 - notas obtidas pelos alunos do Curso de Agronomia, na disciplina BLG 1035 - Botânica Agrícola, turma 11, primeiro semestre de 2012, nas modalidades presenciais e à distância utilizando Moodle. Santa Maria-RS, 2012.

\begin{tabular}{|c|c|c|c|c|c|c|}
\hline & $1^{\circ}$ BIMESTRE & \multicolumn{5}{|c|}{$2^{\circ}$ BIMESTRE } \\
\hline $\begin{array}{l}\text { Aluno } \\
\text { s }\end{array}$ & $\begin{array}{c}\text { Avaliações } \\
100 \% \\
\text { presenciais }\end{array}$ & $\begin{array}{l}\text { Avaliações } \\
50 \% \\
\text { presencias }\end{array}$ & $\begin{array}{c}\text { Avaliações } \\
50 \% \text { via } \\
\text { moodle }\end{array}$ & $\begin{array}{c}\text { Média } \\
\text { (presencial + } \\
\text { moodle) }\end{array}$ & $\begin{array}{l}\text { Média } \\
\text { final }\end{array}$ & Situação* \\
\hline 1 & 5,32 & 2,46 & 1,90 & 4,36 & 4,84 & $\mathbf{A}$ \\
\hline 2 & 4,67 & 1,35 & 0,00 & 1,35 & 3,01 & $\mathbf{R}$ \\
\hline 3 & 7,3 & 2,61 & 3,54 & 6,15 & 7,00 & $\mathbf{A}$ \\
\hline 4 & 5,01 & 0,00 & 0,75 & 0,75 & 2,88 & $\mathbf{R}$ \\
\hline 5 & 6,01 & 2,87 & 0,94 & 3,81 & 4,91 & $\mathbf{R}$ \\
\hline 6 & 6,85 & 4,03 & 4,34 & 8,37 & 7,61 & $\mathbf{A}$ \\
\hline 7 & 5,81 & 2,93 & 3,50 & 6,43 & 6,12 & $\mathbf{A}$ \\
\hline 8 & 6,14 & 0,00 & 0,69 & 0,69 & 3,41 & $\mathbf{R}$ \\
\hline 9 & 6,35 & 2,73 & 0,62 & 3,35 & 4,85 & $\mathbf{A}$ \\
\hline 10 & 7,38 & 3,03 & 3,87 & 6,90 & 7,14 & $\mathbf{A}$ \\
\hline 11 & 2,41 & 0,00 & 0,00 & 0,00 & 1,20 & $\mathbf{R}$ \\
\hline 12 & 8,45 & 3,49 & 2,79 & 6,28 & 7,37 & A \\
\hline 13 & 6,69 & 2,90 & 3,02 & 5,93 & 6,31 & $\mathbf{A}$ \\
\hline 14 & 4,61 & 1,91 & 1,31 & 3,23 & 3,92 & $\mathbf{A}$ \\
\hline 15 & 3,45 & 1,43 & 0,00 & 1,43 & 2,44 & $\mathbf{R}$ \\
\hline 15 & 6,66 & 3,28 & 3,40 & 6,68 & 7,00 & $\mathbf{A}$ \\
\hline 17 & 7,47 & 2,16 & 1,00 & 3,16 & 5,32 & A \\
\hline 18 & 8,99 & 3,71 & 4,22 & 7,93 & 8,46 & A \\
\hline 19 & 5,32 & 2,46 & 1,90 & 4,36 & 4,84 & A \\
\hline 20 & 4,67 & 1,35 & 0,00 & 1,35 & 3,01 & $\mathbf{R}$ \\
\hline 21 & 7,3 & 2,61 & 3,54 & 6,15 & 7,00 & A \\
\hline
\end{tabular}

programático apresentado nas duas modalidades, tendo as avaliações peso 5,0 cada uma, as notas finais do segundo bimestre foram ainda mais baixas, chegando a apresentar nota 0,75 e a desistência de três alunos nas avaliações presenciais e um na modalidade à distância. Para a turma 12, embora as notas tenham sido menores que as do primeiro bimestre, mantiveram-se na grande maioria entre 6,00 e 8,00 .

Sabe-se que a integração das TICs na educação presencial aliada à interdisciplinaridade é desafiadora e pode oferecer suporte à atividade reflexiva, atualizada e contínua, sobre as potencialidades e implicações da inserção dos mediadores tecnológicos no trabalho pedagógico. No entanto, a mediação tecnológica educacional proporciona alocar a produção didática não resultando apenas em estabelecimento repositório virtual e digital. Portanto, é preciso que os professores estejam receptivos às inovações tecnológicas e que isso reflita positivamente no planejamento e no desenvolvimento das aulas realizadas, possibilitando aos alunos produzir e interpretar as novas linguagens do mundo atual e futuro. Além disso, segundo Abegg $\&$ de Bastos (2005), é preciso se dar a reconstrução dos significados das situações e proporcionar uma base teórico-prática para o replanejamento das aulas, sendo que esta instância organizativa-analítica do ensino-investigativo produz conhecimento educacional, gerando e sustentando os processos escolares. Dessa forma, a ação docente, nesta perspectiva, torna-se uma investigação-ação, melhorando não apenas ensino-aprendizagem, mas também a pesquisa educacional.

Esses pressupostos foram parcialmente observados durante o semestre. Estudando os quadros nos dois bimestres e as notas finais, pode-se verificar que a turma 11 obteve as menores notas tanto na modalidade presencial quanto à distância, o que não foi observado para a turma 12 , na qual os alunos obtiveram as maiores notas nas duas modalidades. Além disso, muitas atividades não presenciais não foram efetuadas pelos alunos da turma 11. Estes resultados contribuíram para a reprovação de apenas alunos da turma 11. Nesta turma, doze alunos ficaram em recuperação 
QUADRO 5: notas obtidas pelos alunos do Curso de Agronomia, na disciplina BLG 1035 - Botânica Agrícola, turma 12, primeiro semestre de 2012, nas modalidades presenciais e à distância utilizando Moodle. Santa Maria-RS., 2012.

\begin{tabular}{|c|c|c|c|c|c|c|}
\hline & $1^{\circ}$ BIMESTRE & \multicolumn{5}{|c|}{$2^{\circ}$ BIMESTRE } \\
\hline $\begin{array}{l}\text { Aluno } \\
\mathbf{s}\end{array}$ & $\begin{array}{c}\text { Avaliações } \\
100 \% \\
\text { presenciais }\end{array}$ & $\begin{array}{l}\text { Avaliações } \\
50 \% \\
\text { presencias }\end{array}$ & $\begin{array}{c}\text { Avaliações } \\
50 \% \text { via } \\
\text { moodle }\end{array}$ & $\begin{array}{c}\text { Média } \\
\text { (presencial + } \\
\text { moodle) }\end{array}$ & $\begin{array}{c}\text { Média } \\
\text { final }\end{array}$ & Situação* \\
\hline 1 & 8,06 & 3,59 & 3,34 & 6,93 & 7,50 & A \\
\hline 2 & 8,20 & 2,80 & 3,85 & 6,65 & 7,42 & A \\
\hline 3 & 8,54 & 2,31 & 2,94 & 5,25 & 7,00 & A \\
\hline 4 & 7,21 & 3,48 & 3,81 & 7,29 & 7,25 & $\mathrm{~A}$ \\
\hline 5 & 7,52 & 3,12 & 3,70 & 6,82 & 7,17 & A \\
\hline 6 & 8,09 & 3,50 & 4,01 & 7,51 & 7,80 & A \\
\hline 7 & 6,83 & 1,93 & 3,79 & 5,72 & 6,28 & A \\
\hline 8 & 8,50 & 2,51 & 3,97 & 6,48 & 7,49 & A \\
\hline 9 & 8,88 & 2,07 & 3,85 & 5,92 & 7,40 & A \\
\hline 10 & 8,00 & 3,24 & 3,99 & 7,23 & 7,62 & A \\
\hline 11 & 5,09 & 1,70 & 4,04 & 5,74 & 5,41 & A \\
\hline 12 & 6,47 & 2,57 & 3,81 & 6,38 & 6,43 & A \\
\hline 13 & 7,75 & 2,10 & 4,12 & 6,22 & 7,00 & A \\
\hline 14 & 7,93 & 3,11 & 3,94 & 7,05 & 7,49 & A \\
\hline 15 & 9,37 & 3,09 & 4,04 & 7,13 & 8,25 & A \\
\hline 15 & 9,35 & 3,15 & 3,96 & 7,11 & 8,23 & A \\
\hline 17 & 9,45 & 2,96 & 4,10 & 7,06 & 8,25 & A \\
\hline 18 & 9,01 & 3,06 & 3,64 & 6,70 & 7,85 & A \\
\hline 19 & 8,88 & 3,20 & 4,22 & 7,42 & 8,15 & A \\
\hline 20 & 7,92 & 3,02 & 3,66 & 6,68 & 7,30 & A \\
\hline 21 & 8,51 & 3,26 & 3,81 & 7,08 & 7,79 & A \\
\hline
\end{tabular}

(exame) e $50 \%$ destes reprovaram na disciplina, enquanto que na turma 12 apenas um ficou em recuperação e foi aprovado. Além disso, durante todo o semestre, a turma 11 mostrou-se menos interessada na disciplina, faltando às aulas presenciais, não enviando virtualmente as atividades solicitadas ou quando estas eram enviadas, as respostas foram sempre num nível de conhecimento e interesse baixo quando comparado à turma 12 (dados observados). Possivelmente, este comportamento da turma 11 está refletido nas notas atribuídas às questões constantes nos quadros 1,2 e 3 discutidos acima, concordando com Baccega (1999), onde comenta que no contexto atual, torna-se indispensável a capacidade de pensar a realidade criticamente, de conseguir selecionar a informação e de interrelacionar conhecimentos. Entretanto, os resultados apresentados pelos alunos da turma 12 corroboram com Hernández (2000), segundo o qual as propostas educacionais baseadas no uso de mídias e recursos tecnológicos são fundamentais para ajudar o aluno a compreender a realidade, examinar os fenômenos que o rodeiam de uma maneira questionadora, contribuindo, não só diante das experiências cotidianas, mas também diante de outros problemas e realidades.

\section{CONCLUSÃO:}

As inovações tecnológicas educacionais interferem positivamente no planejamento e no desenvolvimento das aulas realizadas pelo professor e possibilita aos alunos produzir e interpretar estas novas linguagens.

O conteúdo programático das disciplinas em cursos de Graduação desenvolvidos na forma presencial integrada à modalidade a distância contribui para a capacidade dos alunos de problematizar, refletir e repensar criticamente os conteúdos, selecionando as informações e inter-relacionando os conhecimentos.

A integração das tecnologias da informação e comunicação (TIC) na educação presencial é inovadora e motivadora no processo ensino-aprendizagem na graduação, tanto para o professor 
quanto para o aluno.

O resultado satisfatório da integração entre as aulas presenciais e a modalidade a distância, com o apoio do Moodle, depende do perfil do aluno e este deve estar preparado para as mudanças no processo ensino-aprendizagem no sentido de usufruí-las.

\section{REFERÊNCIAS BIBLIOGRÁFICAS}

ALMEIDA, M.E.B; PRADO, M.E.B.B. Integração tecnológica, linguagem e representação. 2009. Disponível em: http://midiasnaeducacao-joanirse. blogspot.com/2009/02/integracao-tecnologica-linguagem-e.html Acesso:out/2010

ANTUNES, C. Utilizando a tecnologia a seu favor. Disponível em: http://www.universia.com.br/materia/imprimir.jsp?id=11941 Acesso:out/2010.

BACCEGA, M.A. A construção do campo comunicação/educação. Comunicação \& Educação, São Paulo, n.141, p. 7-16, jan./abr. 1999.

BARROS, D.M.V.B. Guia didático sobre as tecnologias da comunicação e informação:material para o trabalho educativo na formação docente. Rio de Janeiro:Vieira \& Lent, 2009. 160p.

HERNÁNDEZ, F. Aprendendo com as inovações nas escolas. $1^{a}$ edição, Artmed Editora, Porto Alegre, 2000, 308p.

ABEGG, I; DE BASTOS, F. DA P. Fundamentos para uma prática de ensino-investigativa em Ciências Naturais e suas tecnologias: Exemplar de uma experiência em séries iniciais. Revista Electrónica de Enseñanza de las Ciencias. v.4, n.3, 2005.

KENSKI, V.M. Educação e tecnologias o novo ritmo da informação. CAMPINAS: PAPIRUS, 6 ed. 2010 v.1. $141 \mathrm{p}$.

MARTINSI. M.C. Situando o uso da mídia em contextos educacionais. 2008. Disponível em: http:// midiasnaeducacao-joanirse.blogspot.com/2008/12/ situando-o-uso-da-mdia-em-contextos.html Acesso:out/2010.

MORAES, C.R., VARELA, S. A motivação do aluno durante o processo de ensino-aprendizagem, 2006 Disponível em : http://web.unifil.br/docs/
revista_eletronica/educacao/Artigo_06.pdf . Acesso:out/2010.

SAMPAIO, M.N; LEITE, L. S. Alfabetização tecnológica do professor. 5. ed. Petrópolis: Vozes, 1999.

SOUZA, V. C.; LORENZI, H. Botânica Sistemática: guia ilustrado para identificação das famílias de Fanerógamas nativas e exóticas no Brasil, baseado em APGIII. 3. ed. Nova Odessa/SP: Instituto Plantarum, 2012. 768p. 